\title{
CONTROLE DA ANTRACNOSE EM MARACUJÁ-AMARELO POR DERIVADOS DE CAPIM-LIMÃO (CYMBOPOGON CITRATUS)
}

\author{
G.S. Moura ${ }^{1 *}$, K.R.F. Schwan-Estrada ${ }^{1}$, A.P.F. Alves ${ }^{1}$, G. Franzener ${ }^{2}$, J.R. Stangarlin ${ }^{3}$ \\ ${ }^{1}$ Universidade Estadual de Maringá, Av. Colombo, 5790, CEP 87020-200, Maringá, PR, Brasil. E-mail: \\ bismoura@hotmail.com
}

\section{RESUMO}

\begin{abstract}
O maracujá-amarelo é uma das principais frutíferas cultivadas no Brasil. A conservação póscolheita de frutos de maracujá tem merecido grande atenção visto que o fruto é perecível e está sujeito à rápida deterioração e incidência de micro-organismos patogênicos. Este trabalho teve por objetivo avaliar a atividade antifúngica in vitro de derivados de capim-limão (Cymbopogon citratus) sobre o crescimento micelial, esporulação, germinação de esporos e tamanho de tubos germinativos de Colletotrichum gloeosporioides e in vivo no controle da antracnose sobre frutos de maracujá-amarelo em pós-colheita. Os tratamentos para o ensaio in vitro foram óleo essencial (OE) $\left(0,5,1,5,10,15,25,50\right.$ e $\left.60 \mu \mathrm{L} \mathrm{mL}^{-1}\right)$, extrato bruto aquoso autoclavado (EAA), extrato bruto aquoso filtrado (EAF), hidrolato e citral $(1,5,10,20$ e $25 \%)$ e no ensaio in vivo, os frutos foram tratados com: OE $(0,025 ; 0,05$ e $0,1 \%)$, hidrolato (5 e 10\%), EAA (10\%) e citral (0,1\%). Água destilada foi utilizada como testemunha. Foram avaliadas a incidência e a severidade da antracnose a cada três dias. Os quatro derivados de capim-limão inibiram o crescimento micelial, a esporulação e a germinação de esporos, sendo que maiores valores de inibição foram obtidos nas maiores concentrações testadas e, no crescimento micelial, atingiram 55,8; 54,5; 30,0 e 19,9\% para OE, EAF, EAA e hidrolato, respectivamente. Na avaliação in vivo, OE 0,1\% e EAA $10 \%$ promoveram significativa redução na severidade da antracnose.
\end{abstract}

PALAVRAS-CHAVE: Colletotrichum gloeosporioides, Passiflora edulis f. flavicarpa, pós-colheita.

\begin{abstract}
CONTROL OF ANTHRACNOSE IN YELLOW PASSION FRUIT BY LEMON GRASS (CYMBOPOGON CITRATUS) DERIVATIVES. The yellow passion fruit is a major fruit crop in Brazil. The post-harvest preservation of yellow passion fruits has deserved great attention since the fruit is perishable and subject to a fast deterioration and incidence of pathogenic microorganisms. The aim of this work was to evaluate the in vitro antifungal activity of lemon grass derivatives on the mycelial growth, sporulation, spore germination and length of germ tubes of Colletotrichum gloeosporioides and the effect of essential oil, extract, hydrolate and citral lemon grass (Cymbopogon citratus) for control of anthracnose on the yellow passion fruits. The treatments for the in vitro assay were essential oil (OE) $\left(0.5,1,5,10,15,25,50\right.$ and $\left.60 \mu \mathrm{L} \mathrm{mL}^{-1}\right)$, autoclaved crude aqueous extract (EAA), filtered crude aqueous extract (EAF), hydrolate and citral (1, 5, 10, 20 and 25\%). For the in vivo assay the fruits were treated with: OE $(0.025,0.05$ and $0.1 \%)$, hydrolate (5 and $10 \%)$, EAA $(10 \%)$ and citral $(0.1 \%)$. Distilled water was used as a control. The anthracnose incidence and severity were evaluated every three days. The in vitro test verified that the 4 evaluated derivatives of lemon grass inhibited the mycelial growth, sporulation and spore germination. The higher the concentration of the derivatives, the higher the inhibition, which for the mycelia growth reached $55.8 ; 54.5 ; 30.0$ and $19.9 \%$ for OE, EAF, EAA and hydrolate, respectively. In vivo tests showed that the OE $0.1 \%$ and EAA $10 \%$ promoted a reduction in the anthracnose severity.
\end{abstract}

KEY WORDS: Colletotrichum gloeosporioides, Passiflora edulis f. flavicarpa, post harvest.

${ }^{2}$ Universidade Federal da Fronteira Sul, Laranjeiras do Sul, PR, Brasil.

${ }^{3}$ Universidade Estadual do Oeste do Paraná, Marechal Cândido Rondon, PR, Brasil.

*Este artigo é parte da dissertação de mestrado do primeiro autor apresentada a Universidade Estadual de Maringá, para obtenção do título em Mestre em Agronomia. 


\section{INTRODUÇÃO}

Dentre as frutíferas de expressão econômica no Brasil, a cultura do maracujá ganhou destaque nos últimos anos (ABREu et al., 2009), despertando interesse como opção de diversificação de cultivo. O maracujá mais cultivado no país é Passiflora edulis f. flavicarpa Deg., conhecido como maracujáamarelo ou azedo, sendo amplamente cultivado em países tropicais e subtropicais (ANDRADE; ANDRADE, 2004).

$\mathrm{O}$ fruto do maracujazeiro está sujeito à rápida deterioração causada pelo murchamento e incidência de micro-organismos patogênicos (CAMPOS et al., 2005), que acarretam perdas significativas (Silva et al., 2008). Entre as doenças que afetam a pós-colheita do maracujá-amarelo, a antracnose, causada por Colletotrichum gloeosporioides (Penz.) \& Sacc., é a mais importante (Fischer et al., 2007). Esta doença afeta todos os órgãos aéreos da planta e ocorre com maior intensidade sob condições de umidade e temperatura elevadas, luminosidade reduzida e presença de ferimentos nos frutos podendo causar grandes perdas em pós-colheita (Benato et al., 2002).

Diversos produtos naturais, entre os quais os extratos aquosos e óleos essenciais obtidos de plantas medicinais, têm apresentado potencial no controle de fitopatógenos, tanto por sua ação fungitóxica direta quanto por alterações fisiológicas na planta (SCHWAN-Estrada; STANGARLIN, 2005). Garcia et al. (2008), avaliando efeito de monoterpenos em pós-colheita, concluíram que compostos de plantas medicinais podem representar alternativa no manejo de doenças em pós-colheita, minimizando o impacto causado por fungicidas sintéticos.

Entre as plantas estudadas, tem merecido atenção o capim-limão (Cymbopogon citratus Stapf.). Alguns trabalhos citam resultados promissores com esta planta. SRIDHAR et al. (2003) e Almeida et al. (2009) relataram atividade antifúngica de extratos de $C$. citratus sobre espécies de Colletotrichum e outros fungos causadores de podridão pós-colheita. Também o óleo essencial tem demonstrado atividade antifúngica (SOUZA JúnIOR et al. (2009). ANTHONY et al. (2003) avaliaram outras espécies de Cymbopogon $\mathrm{e}$ obtiveram atividade sobre doenças e características de frutos de banana em pós-colheita. Quanto à atividade dehidrolatos, ainda são escassas as informações, embora potencial antifúngico tenha sido observado sobre alguns agentes causais de doenças em plantas (LozANo et al., 2000; Silva et al., 2009).

Assim, este trabalho teve como objetivo avaliar a atividade antifúngica in vitro de derivados decapimlimão sobre C. gloeosporioides e seu potencial in vivo no controle da antracnose em frutos maracujá-amarelo, sob condições ambiente de armazenamento.

\section{MATERIAL E MÉTODOS}

O presente trabalho foi conduzido no Departamento de Agronomia da Universidade Estadual de Maringá(UEM), Maringá, PR, nos meses de fevereiro ajunho de 2009. Oexperimento in vitro foi conduzido no Laboratório de Fitopatologia, e o experimento in vivo juntamente com a extração dos óleos essenciais foi realizado no Laboratório de Plantas Medicinais.

Folhas frescas de capim-limão foram coletadas no período da manhã, em fevereiro de 2009, no Horto de Plantas Medicinais da Universidade Estadual de Maringá e utilizadas para obtenção do óleo essencial, do extrato bruto aquoso e hidrolato. Para a obtenção do óleo essencial (OE) e hidrolato utilizou-se o método de destilação por arraste a vapor (hidrodestilação) (TeSKe; TRENTINI, 1997).

Para a obtenção do extrato bruto aquoso, as folhas foram trituradas em liquidificador por $2 \mathrm{~min}$ na proporção de $25 \mathrm{~g}$ de folhas frescas em $100 \mathrm{~mL}$ de água destilada para obter extrato a $25 \%$. O extrato bruto aquoso foi autoclavado por $20 \mathrm{~min}$ a $120^{\circ} \mathrm{C}$ a $1 \mathrm{~atm}$. Também foi avaliado o produto comercial citral (Sigma-Aldrich) com formulação $\mathrm{C}_{10} \mathrm{H}_{16} \mathrm{O}$, principal componente do óleo essencial do capim-limão (GUIMARÃEs et al., 2011). O óleo essencial, hidrolato e citral foram filtrados em membranas de ésteres de celulose $(0,22 \mu \mathrm{m}$ e $47 \mathrm{~mm}$ de diâmetro) para esterilização a frio.

Ensaios in vitro foram conduzidos para avaliar a atividade antifúngica direta dos derivados de capimlimão sobre $C$. gloeosporioides. O óleo essencial (OE) foi utilizado nas concentrações de 0,$5 ; 1 ; 5 ; 10 ; 15 ; 25$; 50 e $60 \mu \mathrm{L} \mathrm{mL}^{-1}$. Extrato bruto aquoso autoclavado (EAA), extrato bruto aquoso filtrado (EAF), hidrolato e citral foram utilizados nas concentrações de 1, 5, 10,20 e $25 \%$. O fungo C. gloeosporioides utilizado nos ensaios foi cedido pela Embrapa Cenargen como isolado CEN 419, obtido a partir de frutos de maracujá-amarelo.

Para oensaio decrescimento micelial, os tratamentos OE, EAA, EAF e hidrolato foram incorporados em meio BDA fundente e, em seguida, vertidos em placas de Petri. Duas horas após, um disco de $7 \mathrm{~mm}$ de diâmetro, contendo micélio de C. gloeosporioides com de15 dias de idade, foi repicado para o centro de cada placa que foram mantidas a $25^{\circ} \mathrm{C}$ em escuro. Meio contendoapenas BDA foi utilizado como testemunha. As avaliações foram realizadas através das medições diárias do diâmetro das colônias, iniciadas 48 horas após a instalação do experimento e perduraram até o momento em que as colônias cobriram $2 / 3$ da superfície do meio de cultura. Ao final deste período avaliou-se a esporulação do fungo, realizando-se a contagem dos esporos em câmara de Neubauer ao microscópio óptico, determinando-se o número de esporos $/ \mathrm{cm}^{2}$ de colônia. 
No ensaio de germinação de conídios de C. gloeosporioides, alíquotas de $10 \mu \mathrm{L}$ de suspensão de conídios $\left(2 \times 10^{5}\right.$ esporos $\left.\mathrm{mL}^{-1}\right)$ e $50 \mu \mathrm{L}$ de cada um dos tratamentos (OE, EAF, hidrolato e citral) foram colocadas em poçinhos de placa de ELISA eincubadas em escuro a $25^{\circ} \mathrm{C}$ por 9 horas quando a germinação foi paralisada com $20 \mu \mathrm{L}$ do corante azul algodão + lactofenol. Posteriormente, avaliou-sea porcentagem degerminação deesporos através da contagem de 100 esporos por repetição determinando-se a porcentagem de esporos germinados. Foi também avaliado o tamanho dos tubos germinativos, sendo medidos 10 tubos germinativos por parcela. A contagem e medição foram realizadas ao microscópio óptico com auxílio de régua ocular.

Os dados de porcentagem de germinação foram transformados em $\sqrt{x+0,5}$ para análise estatística. Os ensaios foram conduzidos em delineamento experimental inteiramente casualizado (DIC) com quatro repetições. Os resultados obtidos foram submetidos à análise de variância e estudo da regressão para as concentrações dos derivados, utilizando o software estatístico SISVAR (FERREIRA, 2000). A testemunha absoluta foi comparada com os demais tratamentos pelo teste de Dunnett a 5\% de probabilidade com auxílio do programa SAS versão 8.0 (SAS INSTITUTE INC. 1995).

Ensaio in vivo foi conduzido em pós-colheita de frutos de maracujá-amarelo, cultivados sob sistema orgânico coletados de produtorna cidadede Maringá, PR. Foram selecionados frutos com peso uniforme ( $\pm 200 \mathrm{~g})$, apresentando coloração amarelo verde estádio em que normalmente é realizada a colheita comercial. Os frutos foram levados ao laboratório onde foram lavados em solução de hipoclorito de sódio $0,5 \%(\mathrm{v} / \mathrm{v})$ por $1 \mathrm{~min}$ e enxaguados duas vezes em água destilada. A pós secos, os frutos foram submetidos por $1 \mathrm{~min}$ em cada tratamento: óleo essencial $(0,025 ; 0,05$ e $0,1 \%)$, hidrolato (5 e 10\%), extrato bruto aquoso autoclavado (10\%), citral $(0,1 \%)$ e água (testemunha). Depois da imersão os frutos foram colocados em bandejas e secos em temperatura ambiente $\left(26 \pm 2^{\circ} \mathrm{C}\right.$ e UR $\left.80 \pm 5 \%\right)$. Foram utilizados oito frutos por parcela, com quatro repetições.

Nas primeiras $48 \mathrm{~h}$ de armazenamento, os frutos foram mantidos em câmara úmida, visando a favorecer a ocorrência das doenças pós-colheita e depois permaneceram por quinze dias sob condições ambiente, visando a reproduzir as condições de comercialização, com monitoramento da temperatura e da umidade relativa $\left(26 \pm 2^{\circ} \mathrm{C}\right.$ e UR $\left.80 \pm 5 \%\right)$.

As porcentagens de incidência e severidade da antracnose foram avaliadas concomitantemente e após 3, 6, 9, 12 e 15 dias do tratamento dos frutos. Para análise estatística, os dados foram transformados em arc sen $\sqrt{x+0,5 / 100}$. Para interpretação dos resultados de incidência e severidade da doença, foi calculada a área abaixo da curva de progresso da incidência (AACPI) e da severidade (AACPS) com auxílio do programa Win AACPD (BeLAN et al., 2005). Este procedimento foi adotado por representar um modelo integral e, portanto, considerar a totalidade dos resultados obtidos durante as avaliações (BERGAMIN FILHO, 1995).

\section{RESULTADOS E DISCUSSÃO}

Óleo essencial, extrato aquoso e hidrolato de capim-limão inibiram o crescimento micelial de $C$. gloeosporioides (Fig. 1). Maior inibição foi obtida nas maiores concentrações e atingiram 55,8; 54,5; 30,0 e $19,9 \%$ para OE, EAF, EAA e hidrolato, respectivamente. Alguns trabalhosjá mostraram atividade de $C$. citratus sobreocrescimento micelial defungos (CARNELOSSI et al., 2009; SOUZA JúNIOR et al., 2009). GARCIA et al. (2008), além de verificar inibição do crescimento micelial de fungos do gênero Colletotrichum por parte de compostos monoterpenos de capim-limão, observaram alterações morfológicas nas hifas destes fungos em função dos tratamentos.

Quanto à esporulação de C. gloeosporioides (Fig. 2), todos os tratamentos promoveram redução no número de esporos por $\mathrm{cm}^{2}$ de colônia em relação à testemunha contendo apenas BDA, porém, não foi possível ajustar equação para nenhum derivado, havendo inibição da esporulação em todas as concentrações. Todas as médias dos tratamentos com derivados de capim-limão foram inferiores à testemunha BDA pelo teste de Dunnett a 5\% de probabilidade. Todos os tratamentos promoveram redução superior a 50\% na esporulação em relação à testemunha. Estes resultados indicam que o efeito dos derivados de $C$. citratus sobre a produção de esporos não foi dose-dependente e que houve maior sensibilidade da esporulação aos tratamentos quando comparada ao crescimento micelial. Isso é coerente com o fato de muitos fungos necessitarem de condições específicas para esporulação podendo essa ser inibida em baixas concentrações de compostos antifúngicos.

Quanto ao efeito da autoclavagem no extrato, observou-se que, na concentração de $25 \%$, o EAA apresentou uma inibição do crescimento micelial $35,1 \%$ inferior ao extrato não autoclavado (EAF) podendo-se acreditar na presença de compostos termolábeis no extrato quando consideradoessedado isoladamente. Porém, os resultados de crescimento micelial entre EAA e EAF nas demais concentrações e na esporulação foram semelhantes, sugerindo a presença de compostos ativos termoestáveis. Portanto, estes resultados sugerem que o tratamento térmico por autoclavagem pode provocar algumas alterações na atividade do extrato, porém, sem comprometer em maior grau a atividade antifúngica à C. gloeosporioides. 

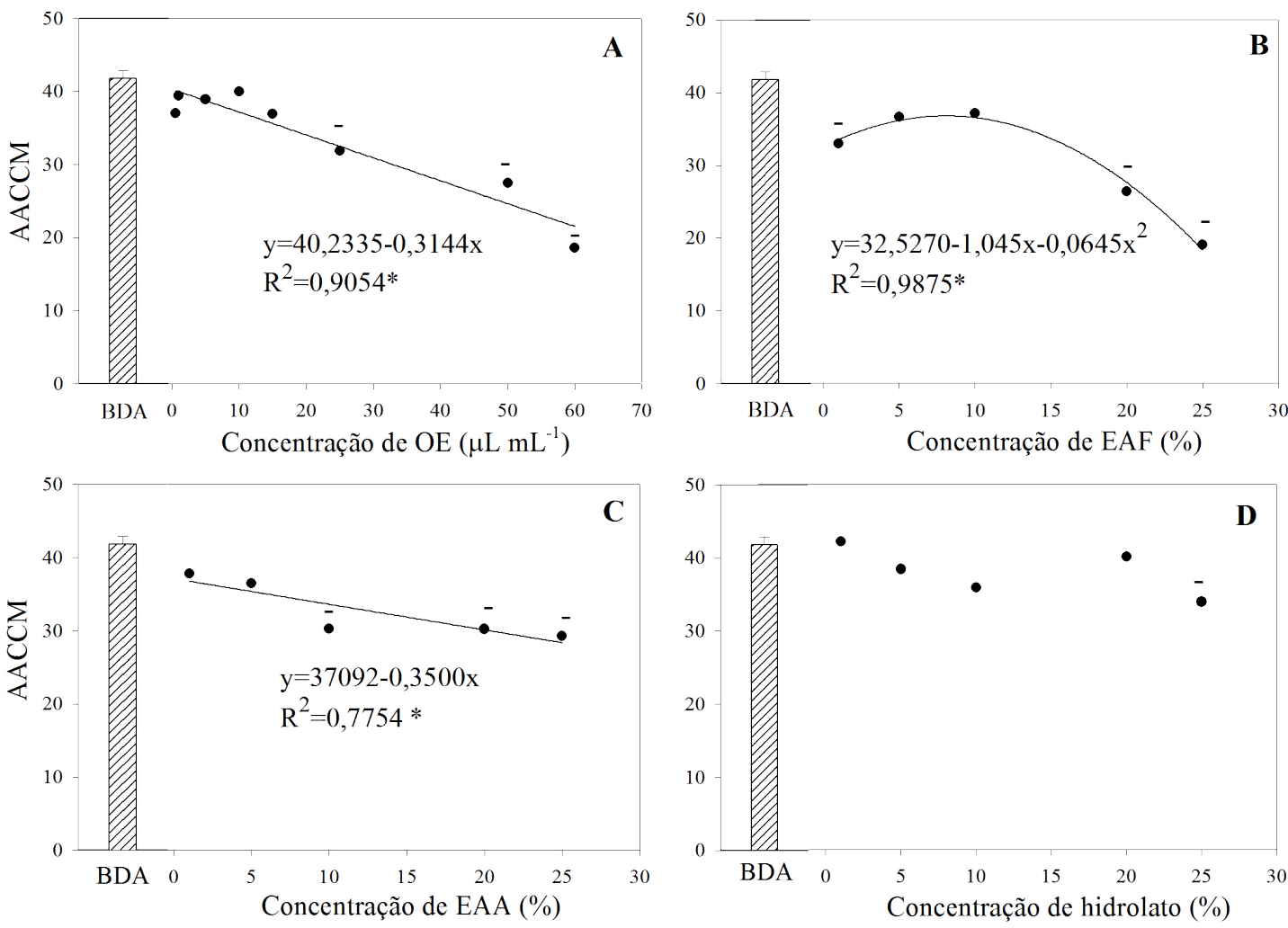

Fig. 1 - Área abaixo da curva de crescimento micelial (AACCM) de Colletotrichum gloeosporioides em função do tratamento com óleo essencial (OE) (A), extrato bruto aquoso filtrado (EAF) (B), extrato bruto aquoso autoclavado (EAA) (C) e hidrolato (D). *significativo no nível de $5 \%$ de probabilidade. (-) difere da testemunha sendo inferior a esta pelo teste de Dunnett a $5 \%$ de probabilidade.
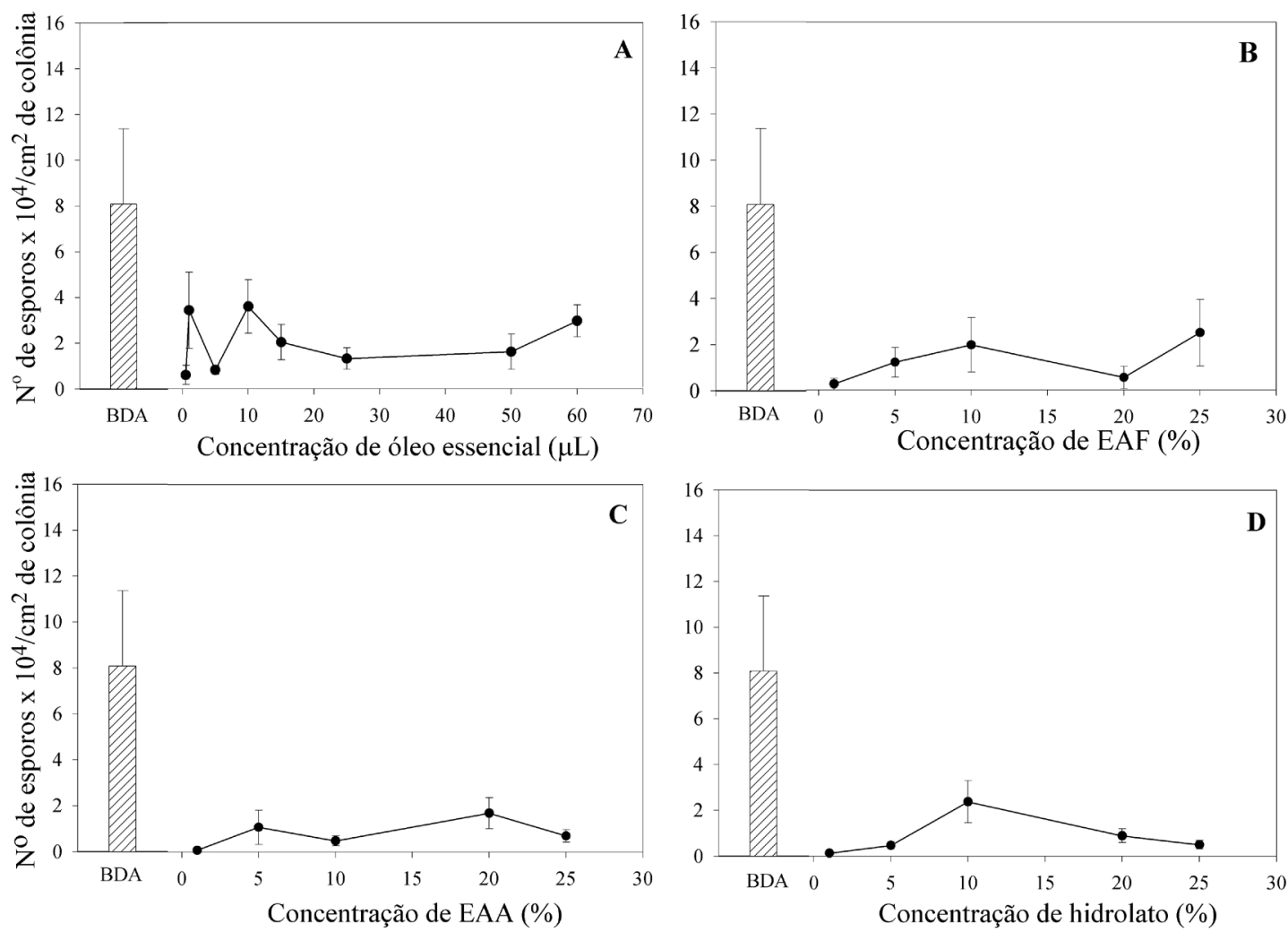

Fig. 2 - Esporulação de Colletotrichum gloeosporioides em função do tratamento com óleo essencial (A), extrato bruto aquoso filtrado (B), extrato bruto aquoso autoclavado (C) e hidrolato (D). Barras representam o erro padrão da média. 
Na testemunha, houve germinação próxima a 98\% indicando alta viabilidade dos esporos (Fig. 3 ). De forma semelhante ao que ocorreu na esporulação, todos os tratamentos contendo derivados de capim-limão promoveram inibição da germinação de esporos em relação à testemunha água pelo teste de Dunnett a 5\% de probabilidade, indicando atividade dos produtos mesmo nas menores concentrações. Não houve ajuste significativo de equação para $\mathrm{OE}$ e hidrolato.

Para o EAF houve ajuste quadrático com ponto de máxima germinação de esporos na concentração de 11,2 do extrato, com inibição de 61,2 e $86,7 \%$ da germinação nas concentrações de 1 e $25 \%$, respectivamente. Maior inibição da germinação de esporos foi obtida com o produto citral (Fig. 3) que, nas concentrações de 20 e $25 \%$, promoveu inibição de $97,7 \%$. Assim, pelo modelo linear ajustado às médias do citral, para cada $1 \%$ de aumento na dose deste produto há a redução de $2,45 \%$ na germinação de esporos de C. gloeosporioides.

Outros trabalhos utilizando derivados de capimlimão, sobretudo oóleo essencial, relatamexpressivos resultados na inibição da germinação de esporos de outros fungos. Os óleos essenciais de C. citratus, Eucalyptus citriodora Hook e Ageratum conyzoides L. inibiram completamente a germinação de esporos do fungo Dydimella bryoniae (Auersw.) Rehm, causador de danos às folhas e frutos de melão (FIORI et al., 2000). TZORTZAKIS; ECONOMAKIS (2007) avaliaram a germinação de esporos de Colletotrichum coccodes Wallr., Botrytis cinerea Pers., Cladosporium herbarum (Pers.) Link e Rhizopus stolonifer (Ehrenb.) Vuill. e também observaram efeito dose-dependente para óleo essencial de C. citratus.

SOUZA JÚNIOR et al. (2009) obtiveram inibição total do crescimento micelial e da germinação de esporos de C. gloeosporioides utilizando o óleo essencial de $C$. citratus a partir da concentração de $1 \mu \mathrm{LLL}^{-1}$. SRIDHAR et al. (2003) e AlmeidA et al. (2009) também relataram atividade antifúngica de extratos de C. citratus sobre espécies de Colletotrichum e outros fungos causadores de podridão pós-colheita.

Todos os tratamentos contendo derivados de capim-limão inibiram o desenvolvimento dos tubos germinativos em relação à testemunha (Fig. 4). Maior inibição foi obtida nas maiores concentrações e atingiram 47,$6 ; 44,4 ; 44,1$ e $42,0 \%$ para $\mathrm{OE}$, citral, hidrolato eEAF, respectivamente. Este efeito significativo dos derivados sobre o desenvolvimento dos tubos germinativos sugerea importância da avaliação desta característica em ensaios dessa natureza, pois a maioria dos ensaios direciona observações apenas sobre o crescimento micelial e germinação de esporos.

A atividade antifúngica observada para OE devese, possivelmente, à presença do citral, seu principal constituinte (GUIMARÃEs et al., 2011). No caso do EAF houve ajuste quadrático, assim como ocorreu sobre o crescimento micelial e germinação de esporos. O ponto de máximo desenvolvimento dos tubos germinativos foi na concentração de 11,1 sendo esta dose muito próxima à obtida nas outras variáveis. Por outro lado, o hidrolato também mostrou atividade antifúngica. Embora o hidrolato possa conter pequena quantidade de óleo essencial, esse reúne, sobretudo, compostos hidrossolúveis, como ácidos, aldeídos e aminas (TESKe; TRENTINI, 1997), assim, é provável que haja maior diversidade de compostos ativos no capim-limão. Estudos de atividade antimicrobiana e controle de doenças de plantas com o uso de hidrolatos ainda são escassos, talvez por se tratar de um derivado mais diluído, mas que, no entanto, não deve ser desprezado por apresentar compostos com significativa atividade antifúngica e possivelmente outros constituintes potenciais. Um dos poucos trabalhos nesse sentido relata a inibição no desenvolvimento dos fungos fitopatogênicos Botrytis alli Munn. e Sclerotium cepivorum Berk. por hidrolatos de alho (Allium sativum L.) e cebola (Allium cepa L.) (LozANo et al., 2000).

Para incidência da antracnose em frutos de maracujá-amarelo não foi observada diferença significativa entre os tratamentos pelo teste deScott-Knott no nível de 5\% de probabilidade (Fig. 5). Na severidade, o efeito dos tratamentos foi mais expressivo sendo que $\mathrm{OE} 0,1 \%$ e EAA $10 \%$ reduziram em aproximadamente $50 \%$ a severidade em relação à testemunha tratada apenas com água. Maior destaque foi para o citral que promoveu incremento na severidade da doença em 79,3\% em relação à testemunha água. Os demais tratamentos não diferiram estatisticamente entre si.

O incremento na doença pelo citral pode ser devidoà toxidezcausada nos frutos. WurYATMOetal. (2003) citaram que o citral é capaz de causar modificação em processos celulares e ser potencialmente tóxico e que, dependendo da concentração e sensibilidade do tecido vegetal, pode causar injúria em frutos. GARCIA et al. (2008) avaliaram o efeito antimicrobiano sobre fitopatógenos de pós-colheita e conservação de frutos tropicais (banana, mamão e abacaxi) de monoterpenos, entre eles o citral. Verificaram que o citral, na concentração de $1 \%$, foi o mais eficiente e que, além de efeito direto sobre os fungos, foi capaz de reduzir em mais de $70 \%$ o diâmetro de lesões nos frutos. Os mesmos autores ainda indicam o uso de óleo essencial como alternativa de manejo no controle defungos em pós-colheita, mas sugerem adaptações como o uso de dispersantes para potencializar os efeitos e evitar toxidez pelo óleo essencial puro em contato direto com frutos sensíveis. ANARUMa et al. (2010) também observaram o potencial do óleo essencial de $C$. citratus no controle da antracnose em frutos de maracujazeiro. 

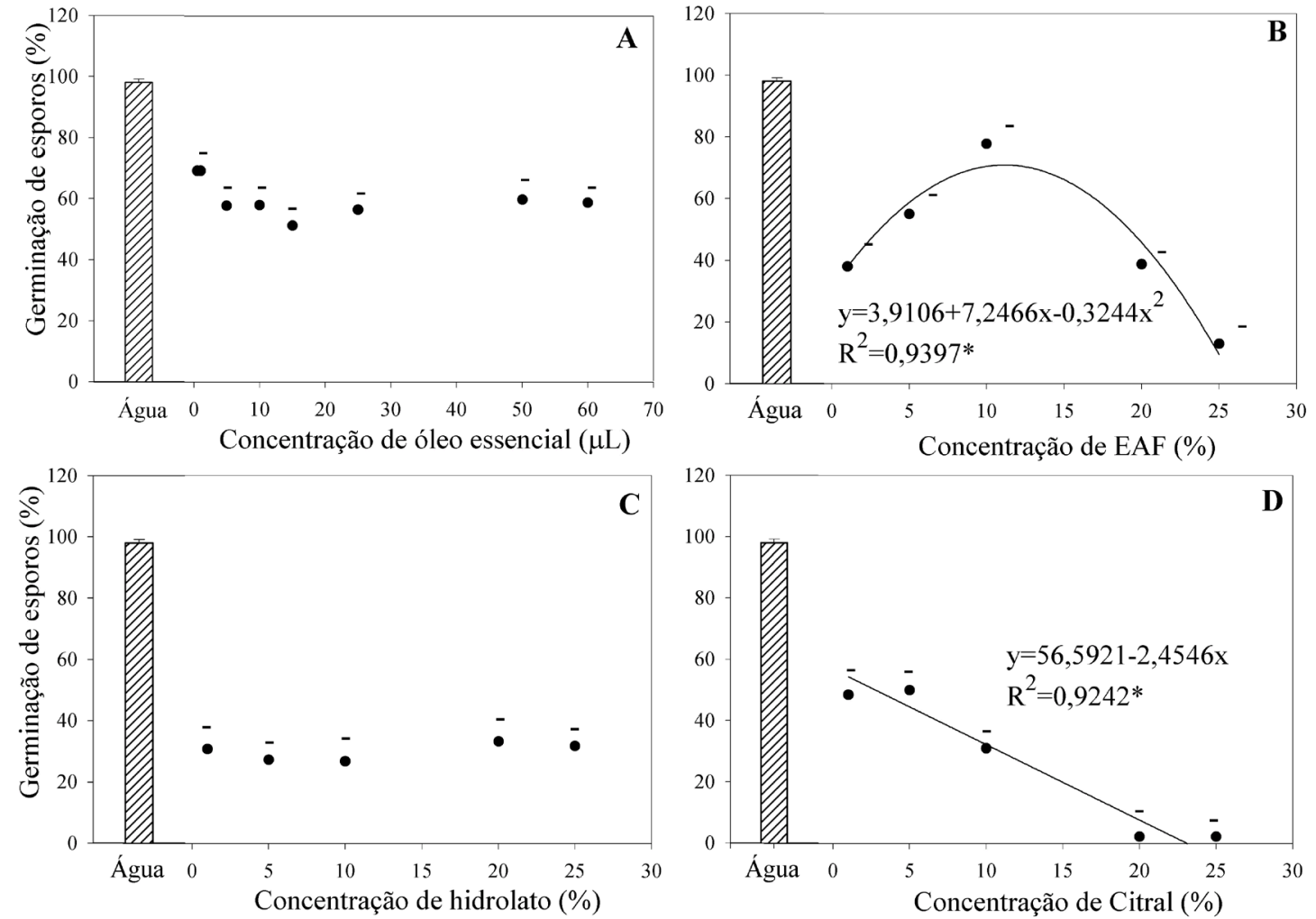

Fig. 3 - Germinação de esporos de Colletotrichum gloeosporioides em função do tratamento com óleo essencial (A), extrato bruto aquoso filtrado (B), hidrolato (C) e citral (D). * significativo no nível de 5\% de probabilidade. (-) difere da testemunha sendo inferior a esta pelo teste de Dunnett a 5\% de probabilidade.
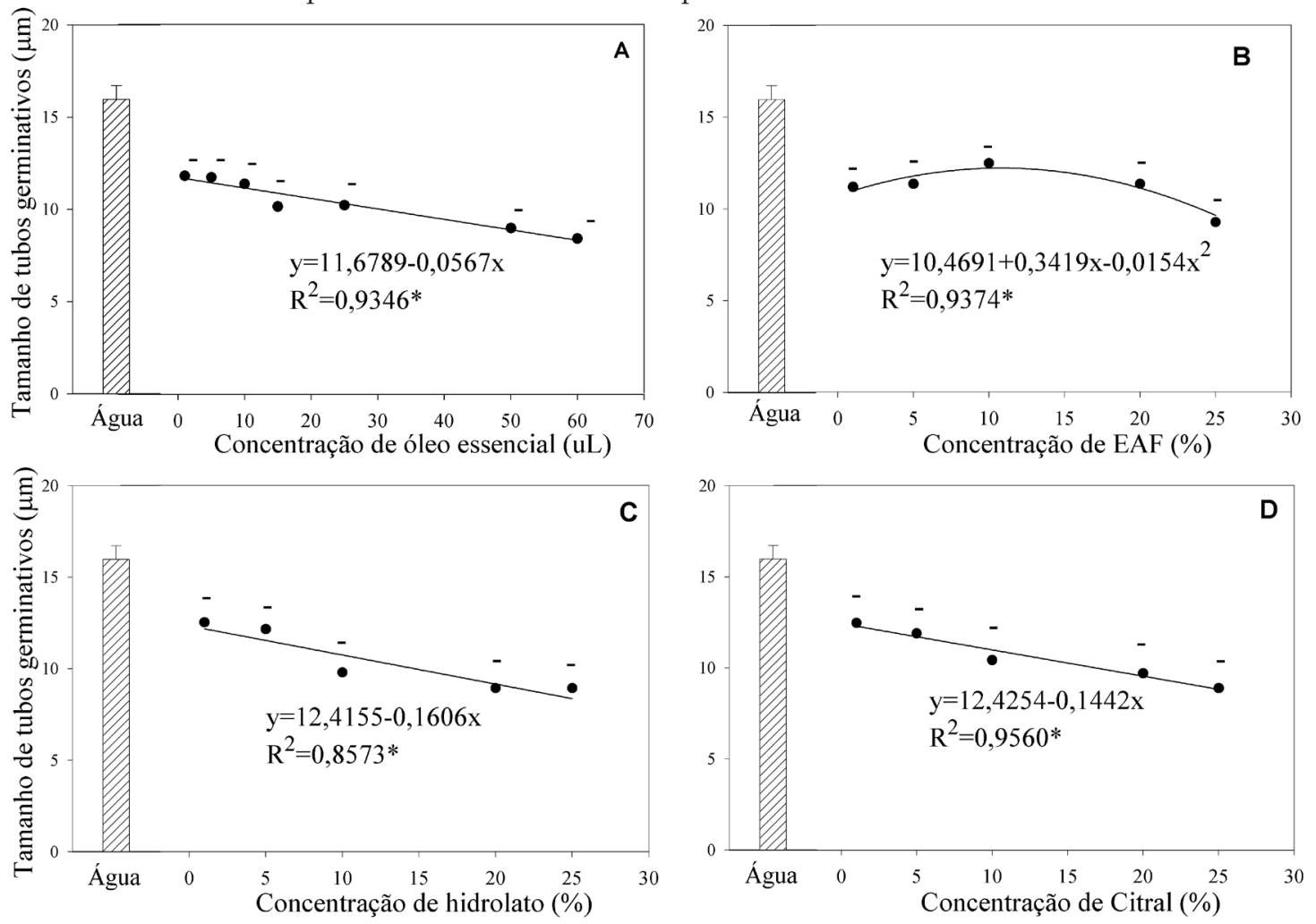

Fig. 4 - Tamanho de tubos germinativos de Colletotrichum gloeosporioides em função do tratamento com óleo essencial (A), extrato bruto aquoso filtrado (B), hidrolato (C) e citral (D). * *significativo no nível de $5 \%$ de probabilidade. (-) difere da testemunha sendo inferior a esta pelo teste de Dunnett a $5 \%$ de probabilidade. 

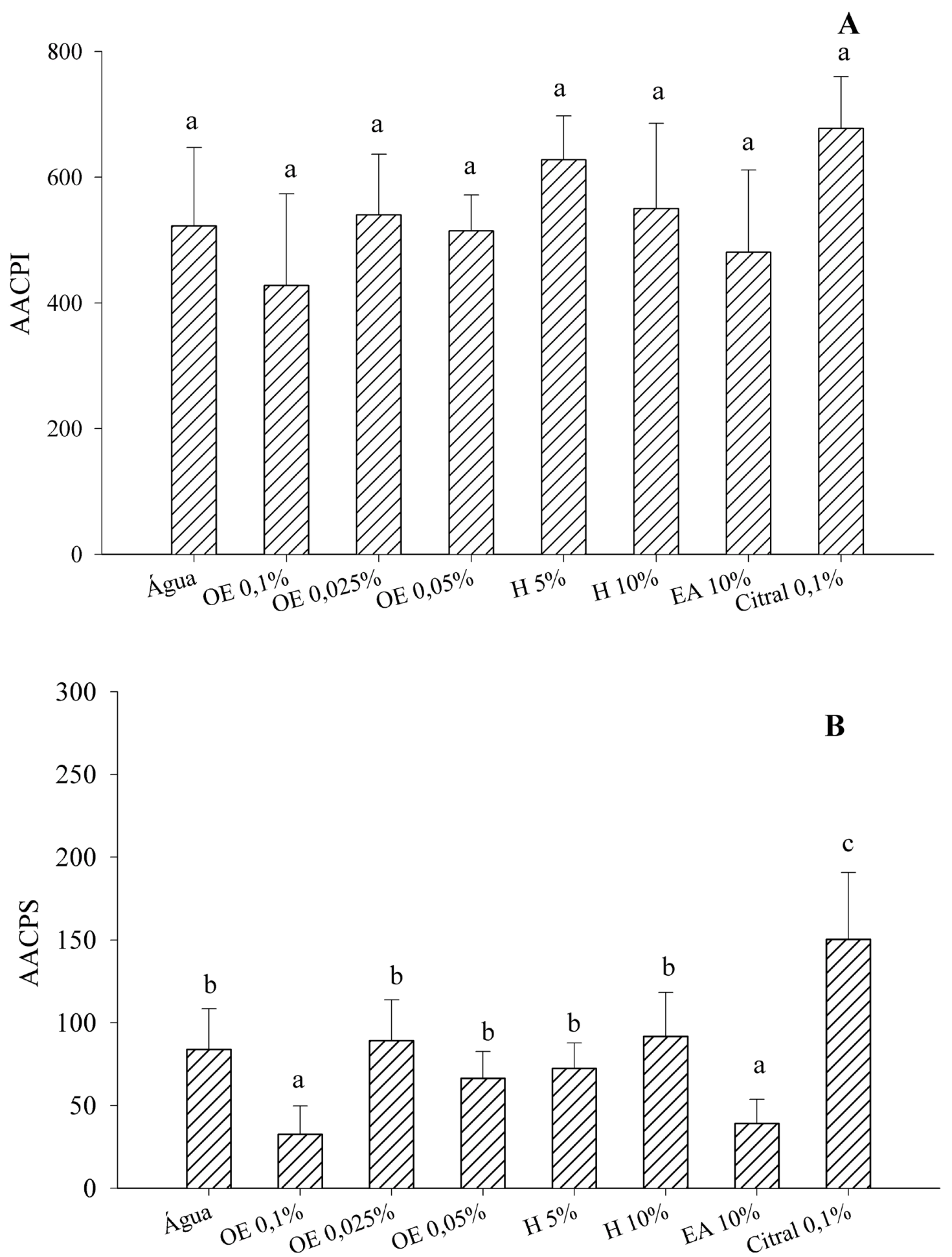

Fig. 5 - Área abaixo da curva de progresso da incidência (A) e da severidade (B) da antracnose em frutos de maracujáamarelo submetidos ao tratamento com derivados de capim-limão. Barras representam o erro padrão da média. Médias seguidas de letras distintas diferem entre si pelo teste de Scott-Knott no nível de 5\% de probabilidade. OE: Óleo essencial; H: Hidrolato; EA: Extrato bruto aquoso autoclavado.

Quanto ao uso de hidrolato, não houve efeito significativo no controle da doença. Embora o hidrolato possa apresentar compostos antifúngicos, estes tendem a estar mais diluídos por conter a água do processo de extração apresentando compostos hidrossolúveis, enquanto o óleo essencial concentra compostos hidrofóbicos (TeSKE, TRENTINI, 1997). Além disso, o efeito positivo no controle da antracnose pelo óleo essencial 
e extrato aquoso pode ser devido a compostos presentes no óleo essencial, como o citral, e que estão presentes também no extrato aquoso ou ao possível efeito sinergístico entre os diferentes compostos, aumentando a eficiência no controle da doença e minimizando o efeito fitotóxico observado para o citral isoladamente.

\section{CONCLUSÕES}

Todos os derivados de capim-limão avaliados apresentaram atividade antifúngica in vitro sobre C. gloeosporioides com destaque para óleo essencial e citral. A atividade por diferentes derivados sugere a presença de maior diversidade de compostos ativos em capim-limão. Estes resultados confirmam a atividade biológica de derivados de $C$. citratus e indicam seu potencial no controle alternativo de $C$. gloeosporioides em maracujá-amarelo.

\section{AGRADECIMENTOS}

À CAPES pela concessão da bolsa de mestrado e à Embrapa Cenargen pelo fornecimento do isolado fúngico.

\section{REFERÊNCIAS}

ABREU, S.P.M.; PEIXOTO, J R.; JUNQUEIRA, N.T.V.; SOUSA, M.A.F. Características físico-químicas de cinco genótipos de maracujazeiro azedo cultivados no distrito federal. Revista Brasileira de Fruticultura, v.31, n.2, p.487491, 2009

ALMEIDA, T.F.; CAMARGO, M.; PANIZI, R.C. Efeito de extratos de plantas medicinais no controle de Colletotrichum acutatum, agente causal da flor preta do morangueiro. Summa Phytopathologica, v.35, n.3, p.196201, 2009.

ANARUMA, N.D.; SCHMIDT, F.L.; DUARTE, M.C.T.; FIGUEIRA, G.M.; DELARMELINA, C.; BENATO, E.A.; SARTORATTO, A. Control of Colletotrichum gloeosporioides (Penz.) Sacc. in yellow passion fruit using Cymbopogon citratus essential oil. Brazilian Journal of Microbiology, v.41, n.1, p.66-73, 2010.

ANDRADE, J.M.B.; ANDRADE, A.B. Características físico-químicas do maracujá amarelo produzido em diferentes épocas em Marumbi-PR. Arquivos da Apadec, v.8, p.219-220, 2004. Suplemento.

ANTHONY, S.; ABEYWICKRAMA, K.; WIJERATNAM, S.W. The effect of spraying essential oils of Cymbopogon nardus, Cymbopogon flexuosus and Ocimum basilicum on postharvest diseases and storage life of Embul banana,
Journal of Horticultural Science \& Biotechnology, v.78, n.6, p.780-785, 2003.

BELAN, H.C.; RITTER, R.A.O.; FÜRSTENBERGER, A.L.F.; CANTERI, M.G. Win AACPD: Software para cálculo da área abaixo da curva de progresso da doença no ambiente Windows. 2005.

BENATO, E.A.; SIGRIST, J.M.M.; HANASHIRO, M.M.; MAGALHÃES, M.J.M.; BINOTTI, C.S. Avaliação de fungicidas e produtos alternativos no controle de podridões pós-colheita em maracujá-amarelo. Summa Phytopathologica, v.28, n.4, p.299-304, 2002.

BERGAMIN FILHO, L. A epidemia como um sistema. In: AMORIM FILHO, A.; KIMATI, H.; AMORIM, L (Ed.). Manual de fitopatologia: princípios e conceitos. 3.ed. São Paulo: Agronômica Ceres, 1995. v.1, p.574-601.

CAMPOS, A.J.; MANOEL, L.; DAMATTO JÚNIOR, E.R.; VIEITES, R. L.; LEONEL, S.; EVANGELISTA, R.M. Tratamento hidrotérmico na manutenção da qualidade pós-colheita de maracujá-amarelo. Revista Brasileira de Fruticultura, v.27, n.3, p.383-385, 2005.

CARNELOSSI, P.R.; SCHWAN-ESTRADA, K.R.F.; CRUZ, M.E.S.; ITAKO, A.T.; MESQUINI, R.M. Óleos essenciais no controle pós-colheita de Colletotrichum gloeosporioides em mamão. Revista Brasileira Plantas Medicinais, v.11, n.4, p.399-406, 2009.

FERREIRA, D.F. Sistema de análise estatística para dados balanceados (SISVAR). Lavras: UFLA/DEX, 2000.

FIORI, A.C.G.; SCHWAN-ESTRADA, K.R.F.; STANGARLIN, J.R.; VIDA, J.B.; SCAPIM, C.A.; CRUZ, M.E.S.; PASCHOLATI, S.F. Antifungal activity of leaf extracts and essential oils of some medicinal plants against Didymella bryoniae. Journal of Phytopathology, v.148, p.483-487, 2000.

FISCHER, I.H.; ARRUDA, M.C.; ALMEIDA, A.M.; GARCIA, M.J.M.; JERONIMO, E.M.; PINOTTI, R.N.; BERTANI, R.M.A. Doenças e características físicas e químicas pós-colheita em maracujá amarelo de cultivo convencional e orgânico no centro oeste paulista. Revista Brasileira de Fruticultura, v.29, n.2, p.254-259, 2007.

GARCIA, R.; ALVES, E.S.S.; SANTOS, M.P.; AQUIJE, G.M.F.V.; FERNANDES, A.A.R.; SANTOS, R.B.; VENTURA, J.A.; FERNANDEDS, P.M.B. Antimicrobial activity and potential use of monoterpenes as tropical fruits preservatives. Brazilian Journal of Microbiology, v.39, p.163-168, 2008.

GUIMARAES, L.G.L.; CARDOSO, M.G.; SOUSA, P.E.; ANDRADE, J.; VIEIRA, S.S. Atividades antioxidante e fungitóxica do óleo essencial de capim-limão e do citral. Revista Ciencia Agronomica, v.42, n.2, p.464-472, 2011. 
LOZANO, C.; CÓRDOBA, S.N.; ÁVILA, C.; VELOSA, R.M. Evaluacion del efecto de hidrolatos de ajo (Allium sativum) y cebolla junca (Allium fistulosum) en el desarollo de los hongos fitopatogenos Botrytis alli y Sclerotium cepivorum. Fitopatologia Colombiana, v.24, p.29-32, 2000.

SAS Institute Inc. SAS language and procedures: Usage. Version 6. Cary NC: SAS Institute, 1995. 373p.

SCHWAN-ESTRADA, K.R.F.,; STANGARLIN J.R. Extratos e óleos essenciais de plantas medicinais na indução de resistência. In: CAVALCANTI, L.S.; DI PIERO, R.M.; CIA, P.; PASCHOLATI, S.F.; RESENDE, M.L.V.; ROMEIRO, R.S. (Ed.) Indução de resistência em plantas a patógenos e insetos, Piracicaba: FEALQ, 2005. p.125-132

SILVA, T.V.; RESENDE, E.D.; VIANA, A.P.; PEREIRA, S.M.F.; CARLOS, L.A.; VITORAZI, L. Determinação da escala de coloração da casca e do rendimento em suco do maracujá-amarelo em diferentes épocas de colheita. Revista Brasileira de Fruticultura, v.30, n.4, p.880-884, 2008.

SILVA, A.C.; SALES, N.L.P.; ARAÚJO, A.V.; CALDEIRA JÚNIOR, C.F. Efeito in vitro de compostos de plantas sobre o fungo Colletotrichum gloeosporioides Penz. isolado do maracujazeiro. Ciência e Agrotecnologia, v. 33, p.1853-1860, 2009. [Edição especial].
SOUZA JÚNIOR, I.T.S.; SALES, N.L.P.; MARTINS, E.R. Efeito fungitóxico de óleos essenciais sobre Colletotrichum gloeosporioides isolado do maracujazeiro amarelo. Biotemas, v.22, n.3, p.77-83, 2009.

SRIDHAR, S.R.; RAJAGOPAL, R.V.; RAJAVEL, R.; MASILAMANI, S.; NARASIMHAN, S. Antifungal activity of some essencial oils. Journal of Agricultural and Food Chemistry, v.51, p.7596-7599, 2003.

TESKE, M.; TRENTINI, A.M.M. Herbarium - compêndio de fitoterapia. Curitiba: Herbarium, 1997. 317p.

TZORTZAKIS, N.G.; ECONOMAKIS, C.D. Antifungal activity of lemongrass (Cympopogon citratus L.) essential oil against key postharvest pathogens. Innovative Food Science E Emerging Technologies, v.8, n.2, p.253-258, 2007.

WURYATMO, E.; KLIEBER, A.; SCOTT, E.S. Inhibition of citrus postharvest pathogens by vapor of citral and related compounds in culture. Journal of Agricultural and Food Chemistry, v.51, p.2637-2640, 2003.

Recebido em 20/5/11

Aceito em $7 / 7 / 12$ 